\title{
Flow cytometry in the exploration of the physiopathology of occupational lung disease
}

\author{
A D Curran
}

\begin{abstract}
Flow cytometry is a simple analytical technique used for the investigation of cells taken from various sources. Cells are identified by both their physical characteristics and the presence or absence of specific molecules on the cell surface. These molecules may be either phenotypic, or induced by a specific stimulus. Flow cytometry has been used to identify the nature and extent of the immune response in several occupational respiratory conditions including occupational asthma, irritant induced respiratory problems, and asbestos related lung disease. Also, it may be of value in monitoring workplace exposure to some hazardous materials. Although of limited diagnostic value at present, the technique has provided an insight into the modulation of immune cells, and their function, in people exposed to hazardous materials in the workplace. In this review, the principals of flow cytometry will be explored and the use of flow cytometry to investigate occupational respiratory disease will be discussed.

(Occup Environ Med 1999;56:742-746)
\end{abstract}

Keywords: flow cytometry; occupational; lung disease

\section{What is flow cytometry?}

BASIC PRINCIPLES

Flow cytometry has been used for many years to identify, characterise, and count immune cells in several diseases including leukaemia and human immunodeficiency virus (HIV) infection. In its most basic form, it can be used to identify specific markers on the surface of cells. Variations on this theme also enable the technique to measure markers within cells, to assess enzyme activity within cells, and to identify cells in particular stages of the cell cycle. ${ }^{12}$ After a sample has been taken for investigation, it usually requires only a small amount of processing before analysis by the flow cytometer. When the sample has been introduced into the instrument, a stream of single cells is created, and each cell is analysed in turn. The cells pass through a beam of laser light of defined wavelength, and the instrument collects a large amount of data about each cell. The forward and side scatter of laser light by the cell gives information on its physical characteristics (size and granularity, figure 1), and the fluorescence of specific probes on or within the cell gives information about the phenotype, activation state, enzymatic activity, apoptotic state, cell cycle stage, or viability of the cell being analysed, depending on the technique

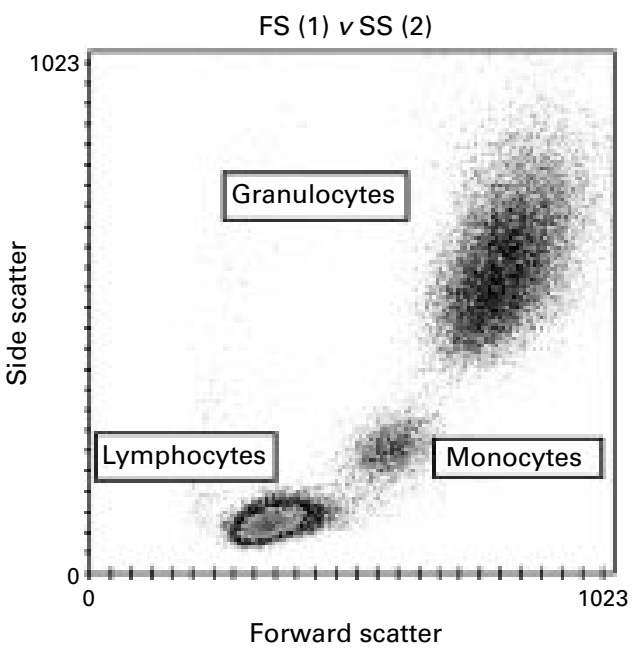

Figure 1 Forward and side scatter characteristics of a lysed human peripheral blood sample. Three distinct populations can be identified from the analysis of these physical characteristics (lymphocytes, monocytes, and granulocytes).

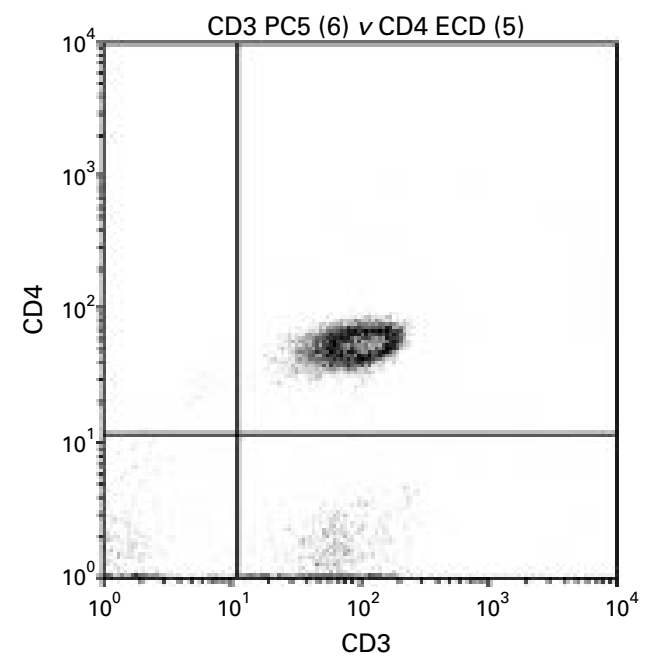

Figure 2 Fluorescence characteristics of lymphocytes stained with monoclonal antibodies to T cells (CD3) and the helper T cell subset $(C D 4+)$. The large population of cells are the double positive helper T cell subset $(C D 3+C D 4+)$.

used (figure 2). Up to four fluorochrome labelled monoclonal antibodies can be used, allowing the coexpression of multiple markers to be measured in a single sample.

IDENTIFICATION OF CELLS

The information generated by the instrument allows subpopulations of cells to be identified and counted. The principle underpinning identification is the presence of markers on the cell surface which are specific for particular 
Table 1 Phenotypic markers of mature leucocyte subpopulations (also, all human leucocytes express CD45, the pan-leucocyte marker)

\begin{tabular}{ll}
\hline Cell type & Immunophenotype \\
\hline All T cells & CD3+ \\
Helper T cells & CD3+CD4+ \\
Cytotoxic or supressor T cells & CD3+CD8+ \\
B cells & CD19+ \\
Monocytes & CD14+ \\
NK cells & CD3-CD56+/CD16+ \\
Neutrophils & CD16+CD11b \\
Eosinophils & Depolarised light \\
\hline
\end{tabular}

immune cells. Identification of cells expressing a particular immunophenotype is achieved through the use of monoclonal antibodies tagged with fluorescence which bind exclusively to the markers of interest. An international system for classifying leucocyte cell surface antigens has been adopted, ${ }^{3}$ with each cell surface marker being given a CD (cluster of differentiation) antigen number; there are now in excess of 166 different cell surface antigens recognised by this system. Table 1 shows the combinations of antigens which are commonly used in flow cytometry for the immunophenotyping of immune cells. For some cell types, however, there is no combination of markers that is unique for the cell type. Therefore, an alternative approach has to be used that makes use of other cell specific properties. Eosinophils, for example, express a similar combination of cell surface makers to neutrophils, but they do differ in their ability to scatter depolarised light. This feature of eosinophils has been sucessfully used in their investigation by flow cytometry. ${ }^{4}$ Where flow cytometry can provide particularly useful information, however, is in the identification and measurement of markers on the cell surface and within the cell that are only expressed in response to a specific stimulus. For example, asthmatic subjects have been shown to possess increased numbers of helper $\mathrm{T}$ cells (CD4+) expressing the interleukin-2 receptor (CD25), but the concentration of these activated helper cells drops in response to inhaled glucocorticosteroids. ${ }^{5}$ Table 2 lists some of the additional markers which can be used to characterise immune cells.

SAMPLES SUITABLE FOR ANALYSIS BY FLOW CYTOMETRY

Many sample types lend themselves to analysis by flow cytometry, and standard protocols now exist for most materials. Peripheral blood is most often used, as it is easy to obtain and process, but induced sputum, ${ }^{6}$ cell culture material, ${ }^{7}$ and bronchoalveolar lavage fluid

Table 2 Cell surface markers expressed by immune cells after external stimulus-for example, exposure to toxic agent

\begin{tabular}{|c|c|}
\hline Marker & Comments \\
\hline CD25 & $\begin{array}{l}\text { Activation marker (interleukin } 2 \text { receptor) expressed on } \mathrm{T} \text { cells, } \mathrm{B} \text { cells, } \\
\text { and monocytes }\end{array}$ \\
\hline CD69 & Activation marker on $\mathrm{T}$ cells, B cells, and NK cells \\
\hline CD54 & Intracellular adhesion molecule (ICAM1) expressed by various cells \\
\hline $\mathrm{CD} 23$ & The low affinity IgE receptor (expressed by B cells) \\
\hline CD45RA & Expressed by "naive" $\mathrm{T}$ cells \\
\hline $\mathrm{CD} 45 \mathrm{RO}$ & Expressed by "memory" $\mathrm{T}$ cells \\
\hline CD11b & $\begin{array}{l}\text { Adhesion molecules expressed by NK cells and some granulocytes: } \\
\text { expression is upregulated by inflammatory mediators }\end{array}$ \\
\hline
\end{tabular}

$(\mathrm{BALF})^{8}$ have all been successfully analysed with this technique. Tissues such as spleen, thymus, lymph nodes, and tumour material can also be analysed but require more complex processing, usually involving enzymatic digestion of the tissue to release the component cells

ADVANTAGES AND DISADVANTAGES OVER OTHER TECHNIQUES

Flow cytometry offers considerable advantages over other cellular tests as it is rapid, simple to perform, and requires only small amounts of sample. Also, the information which it provides can be engineered to be specific for a particular cell type. For example, it not only measures relative concentrations of cytokine, but can also tell you how much cytokine is present in helper $\mathrm{T}$ cells compared with cytotoxic $\mathrm{T}$ cells. There are, of course, disadvantages to this technique also, primarily its cost. Both the equipment required to run the analyses and the reagents used to prepare the samples are expensive. Also, some samples have to be analysed within a few hours of collection, which can make the use of this technique for workplace studies problematic.

\section{How can it be used to explore the mechanisms of occupational lung disease?}

Many occupational and environmental diseases have an aetiology which involves changes in immune cells. Flow cytometry lends itself to the investigation of these processes, as it can monitor rapid changes in cells resulting from short lived insults. Therefore, flow cytometry has been used to study the cellular mechanisms responsible for various occupational respiratory diseases including occupational asthma, irritant induced respiratory problems, asbestosis, and chronic obstructive pulmonary disease (COPD) related to work.

OCCUPATIONAL ASTHMA

Much of the work in this area has been based on the observation that peripheral blood from patients with acute asthma contains increased numbers of inflammatory cells which can be identified by flow cytometry. ${ }^{9}$ In particular, a considerable increase in $\mathrm{T}$ cell activation markers such as CD25 (the interleukin-2 receptor) was identified when compared with control subjects. Furthermore, these CD25 positive lymphocytes were exclusively of the CD4 positive (helper $\mathrm{T}$ cell) phenotype. Although the involvement of the inflammatory response in the pathogenesis of idiopathic and work related asthma now seems clear, the role of inflammation in the production of symptoms after low molecular weight chemical exposure in the workplace is less well documented, although a review by Mapp et $a l^{10}$ emphasised the importance of the cellular response when considering the respiratory sequelae resulting from chemical exposure. Some of the findings in atopic asthmatic patients have been reproduced in patients with asthma induced by toluene diisocyanate, a known sensitiser and also a low molecular weight irritant. ${ }^{11}$ In this study, flow cytometry 
was used to show that late asthmatic reactions induced by toluene di-isocyanate were associated with an increase in the numbers of CD8+ (cytotoxic or supressor) $\mathrm{T}$ cells and eosinophils. These findings are different from the increase in the activation of helper $\mathrm{T}$ cells reported in atopic asthmatic subjects, but the increase in eosinophils is entirely consistent. A similar study investigated the cellular responses to plicatic acid after inhalation. ${ }^{12}$ Flow cytometry showed that although there were some small differences in the immune cell end points measured, these were not of the same scale as those found in atopic asthmatic subjects. With flow cytometry, we have been able to show a difference in the immune cell profile between workers exposed to different respiratory hazards, but reporting similar upper and lower respiratory symptoms. ${ }^{13}$ Phenotypic and inducible cell surface makers were measured in the peripheral blood of bakers exposed to wheat flour, who reported work related respiratory symptoms. The same cell surface markers were measured in glass bottle manufacturers reporting similar symptoms, but exposed to a range of irritant chemicals. The bakers showed activation of helper $\mathrm{T}$ cells, which was consistent with the changes found in mild to severe asthmatic subjects. However, the bottle workers showed a very different pattern of immune cells, with a significant reduction in total $\mathrm{T}$ cells being found. ${ }^{14}$ Other studies have used flow cytometry of peripheral blood to identify cells involved in the aetiology of the asthmatic response a few hours after exposure to an allergen in sensitised people. For example, the nature and extent of the $\mathrm{T}$ cell response before, during, and after allergen challenge in subjects with atopic asthma has been characterised. ${ }^{15}$ The analysis performed in this study was more detailed, with several phenotypic and activation markers being measured. In particular, the analysis showed that 2 and 24 hours after challenge there was a significant increase in $\mathrm{CD} 45 \mathrm{RO}+\mathrm{CD} 25+\mathrm{T}$ helper cells compared with the baseline values. No such increases were found in an isocapnic cold air hyperventilation challenge in the same subjects. These studies have given a valuable insight into the cellular mechanisms responsible for both environmental and occupational respiratory disease, and may ultimately lead to diagnostic tests with increased sensitivity and specificity. All of these studies have used flow cytometry to help in the understanding of the cellular mechanisms in occupational asthma, with the assumption that significant changes in immune state and function may have serious health consequences for the exposed person. However, some studies have used flow cytometry to show a beneficial effect resulting from immune modulation. For example, Kolopp-Sarda $e t a l^{16}$ looked at 116 healthy workers exposed to flour dust and showed that there was a significant alteration in peripheral blood lymphocyte subsets compared with controls. In particular, CD57+ cells (NK cells) and CD4+CD29+ were decreased. Interestingly, this finding was similar to that in atopic patients undertaking desensitisation treatment. Therefore, the au- thors suggest that these small, but significant changes in the immune system may be responsible for the healthy state of the workers by limiting the effects of repeated exposure to wheat flour inhalation.

\section{ASBESTOSIS AND COPD}

Flow cytometry has been used to investigate immune changes in workers exposed to asbestos; of particular interest has been the balance of $\mathrm{T}$ cell subsets in both peripheral blood and bronchoalveolar lavage fluid (BALF). A study of 122 workers exposed to asbestos (mean exposure 23 years) was performed to investigate the relation between asbestos related pleural plaques and interstitial lung disease and immune imbalances in peripheral blood and BALF. ${ }^{17}$ The BALF showed an increase in the percentage of CD8 positive cells in workers exposed to asbestos, which was accompanied by a decrease in CD8 positive cells in peripheral blood. The study also showed that an increase in the CD4/CD8 ratio in BALF was associated with pleural thickening. The possibility of using lymphocyte proportions in BALF to predict the subsequent clinical course of asbestos related disease has also been investigated. ${ }^{18}$ The study identified a subgroup of such workers with a $\mathrm{T}$ cell alveolitis, which could be identified by flow cytometry. Although this group had no present excess of asbestos related disease, it was suggested that they may be at risk of future asbestos related disease. Flow cytometry has also been used to characterise the chromosomal state of tumours associated with malignant mesothelioma, ${ }^{19}$ and the responses of alveolar macrophages to different types of fibrogenic particles. ${ }^{20}$ Interestingly, chrysotile and crocidolite asbestos as well as crystalline silica were able to induce the inducer or immune activator phenotype in alveolar macrophages (RFD1+), whereas titanium dioxide or wollastonite were not.

Abnormalities in immune function have not been well characterised in COPD with flow cytometry, and no workplace studies have been reported to date. However, some recent non-workplace studies have shown that there may be potential for this technique to investigate the mechanisms responsible, as abnormal expression of neutrophil adhesion molecules accompanied by some endothelial dysfunction have been shown, along with perturbations in lymphocyte subsets in peripheral blood. ${ }^{21} 22$

\section{IRRITANT EXPOSURE}

Workplace and environmental exposure to non-sensitising, but toxic materials may also cause changes in the proportions of immunologically important cell types, and increase their state of activation. For example, a study of 71 workers exposed to styrene and 65 control subjects used flow cytometry to characterise the immune state of these people. Many immunological markers were measured in this study, and workers exposed to styrene showed a modified distribution of lymphocyte subsets, with a decrease in total T lymphocytes (CD3+ and CD4+) and an increase in B cells (CD19+) and NK cells (CD56+CD16+/-). ${ }^{23}$ Further- 
more, these changes were related to the exposure of the person to styrene. A recent study of children exposed to high levels of fungal contamination in their homes used flow cytometry to show a significant increase in memory $\mathrm{T}$ cells $(\mathrm{CD} 3+\mathrm{CD} 45 \mathrm{RO}+)$ and a reduced $\mathrm{CD} 4 / \mathrm{CD} 8$ ratio compared with an unexposed control population. The differences were not explained by confounding factors such as house dust mite or pet ownership, suggesting that exposure to fungal contamination leads to chronic stimulation of children's lymphocytes. ${ }^{24}$ With flow cytometry, Muller-Suur et $a l^{25}$ investigated the lymphocytes present in BALF from workers exposed to swine dust. Activated $\mathrm{T}$ lymphocytes (CD25+ and CD69+) increased considerably within 3 hours of exposure, suggesting a role for $\mathrm{T}$ cells in the inflammatory response to inhaled swine dust.

A study of firefighters, who were repeatedly exposed through their work to irritating, asphyxiating toxic gases and aerosols, investigated the cell subsets found in BALF from 13 non-smoking firefighters. An increase in lymphocytes was found, and alveolar macrophage fluorescence was increased in two of 13 volunteers. This and an increase in other markers, indicated that these changes could be temporary natural defence mechanisms to the respiratory insult, thereby potentially protecting the firefighters from long term damage. ${ }^{26}$ Other studies have used flow cytometry to show that workplace exposure to a potentially toxic material results in no detectable immunotoxic effect. For example, a study of 145 lead workers showed that there was no difference in most $\mathrm{T}$ cell markers measured compared with 84 unexposed controls. ${ }^{27}$

\section{EXPOSURE MONITORING}

Flow cytometry has also been suggested to be of value in monitoring exposure to workplace hazards. Metallothionines are a family of low molecular weight proteins that are rapidly induced in cells in response to various environmental agents including heavy metals, oxidising chemicals, and radiation. Biologically they serve to attenuate cellular damage induced by these toxic insults. Flow cytometry has been used with a monoclonal antibody specific for the protein to determine the relative cellular concentrations of metallothionine in human peripheral blood lymphocytes treated in vitro with cadmium. ${ }^{28}$ Lymphocytes increased in a time and dose dependent fashion after treatment with cadmium at concentrations as low as $0.3 \mu \mathrm{M}$. Furthermore, T cells (both CD4+ and CD8+ subsets) expressed higher concentrations of metallothionine than other lymphocyte subsets (B cells, NK cells). Also, the flow cytometric technique could detect a polymorphism in this protein, shown by differential levels of fluorescence. Therefore the authors suggested that the measurement of this protein could be used to assess human exposure to toxic metals, and other workplace and environmental stresses.

We have examined the potential of flow cytometry to monitor exposure to endotoxin (a common contaminant of organic dusts), through the measurement of CD14 on monocytes. ${ }^{29}$ In an in vitro model of exposure, CD14 was significantly increased on monocytes from human volunteers after exposure to endotoxin (as lipopolysaccharide). No increase was found with control materials. More recent work has shown that this increase in monocyte CD14 also occurs in the workplace in people exposed to endotoxin, but not in people who have no exposure (personal communication). We suggest that the measurement of CD14 by flow cytometry could be a useful marker of exposure to an endotoxin.

\section{Current and future impact of this technology}

The full capabilities of flow cytometry have yet to be realised in the field of occupational and environmental medicine. At present it has little diagnostic value, but it is already making a considerable contribution to our understanding of the basic immunological processes involved in the aetiology of occupational diseases. All the studies described have only used the ability of this technique to identify changes in expression of phenotypic and inducible cell surface molecules. Studies have yet to make use of its ability to measure multiple end points from the same sample-for example, phenotypic markers, activation markers, apoptotic state, enzymatic activity, cell cycle stage. This would be a major advantage for occupational diseases with a complicated cellular aetiology, where a single end point approach is of limited value. A recent advance in this field is the development of reagents which allow enzyme activity within cells to be measured. Essentially, cells are incubated with a substrate that releases a fluorochrome after enzyme activity. The fluorochrome can then be measured by flow cytometry. We have used this technique to investigate the in vitro action of colophony on monocytes and neutrophils, and have shown that the interaction between immune cells and chemical sensitisers can result in the production of reactive oxygen species, whereas other control materials do not ${ }^{30}$; we have recently obtained similar results with isocyanates. Flow cytometry is, therefore, showing an alternative immune mechanism to explain the respiratory consequences of exposure to these low molecular weight chemicals, where other techniques had not proved successful.

\section{Conclusions}

Flow cytometry is a simple technique, which yields large amounts of useful data on the immune state of people exposed to toxic agents. The full impact of this emerging technology is yet to be realised in occupational and environmental medicine. Although it has provided very useful information in mechanistic studies, simple cell immunophenotyping, and assessment of activation state, it is of limited use in the diagnosis of occupational disease at present. More recent advances in this technology have yet to be used in this field, but initial studies with flow cytoenzymology have already provided very interesting data. 
1 Ormerod MG, ed. Flow cytometry: a practical approach. New York: Oxford University Press, 1990

2 Parker JW, Adelsberg B, Azen SP, et al. Leukocyte immunophenotyping by flow cytometry in a multisite study: standardisation, quality control, and normal values in the transfusion safety study. Clin Immunol Immunopathol 1990;55:187-220.

3 Schlossman SF, Boumsell L, Gilks W, et al, eds. Leukocyte typing V: white cell differentiation antigens. New York: Oxford University Press, 1995.

4 in't Veen JC, Grootendorst DC, Bel EH, et al. CD11b and L-selectin expression on eosinophils and neutrophils in blood and induced sputum of patients with asthma compared with normal subjects. Clin Exp Allergy 1998;28: 606-15.

5 Corrigan CJ, Hamid Q, Noth J, et al. Peripheral blood CD4 but not CD8 T-lymphocytes in patients with exacerbation of asthma transcribe and translate messanger RNA encoding cytokines which prolong eosinophil survival in the coning cytokines which prolong eosinophil survival in the contherapy. Am 7 Respir Cell Mol Biol 1995;12:567-78.

6 Grootendorst DC, Sont JK, Willems LN, et al. Comparison of inflammatory cell counts in asthma: induced sputum of inflammatory cell counts in asthma: induced sputum v Allergy 1997;27:769-79.

7 Krunkosky TM, Fischer BM, Akley NJ, et al. Tumor necrosis factor $\alpha$ (TNF $\alpha)$-induced ICAM-1 surface expression in airway epithelial cells in vitro: possible signal transduction mechanisms. Ann N Y Acad Sci 1996;796:30-7.

8 Lohmeyer J, Friedrich J, Rosseau S, et al. Multiparameter flow cytometric analysis of inflammatory cells contained in bronchoalveolar lavage fluid. F Immunol Methods 1994;172: 59-70.

9 Corrigan CJ, Hartnell A, Kay AB. T lymphocyte activation in acute severe asthma. Lancet 1988;8595:1129-32.

10 Mapp CE, Saetta M, Maestrelli P, et al. Mechanisms and pathology of occupational asthma. Eur Respir f 1994;7: pathology

11 Finotto S, Fabbri LM, Rado V, et al. Increase in numbers of CD8 positive lymphocytes and eosinophils in peripheral
blood of subjects with late asthmatic reactions induced by blood of subjects with late asthmatic reactions indu
toluene diisocyanate. $B$ f Ind Med 1991;48:116-21.

12 Frew A, Chang JH, Chan $\mathrm{H}$, et al. T-lymphocyte responses to plicatic acid-human serum albumin conjugate in occupational asthma caused by western red cedar. F Allergy Clin Immunol 1998;101:841-7.

13 Curran AD, Gordon SB, Morice AH, et al. Expression of lymphocyte cell surface markers in workers exposed to different respiratory hazards: biomarkers of occupational respiratory disease? Biomarkers 1997;2:367-71.

14 Gordon SB, Curran AD, Turley A, et al. Glass bottle workers exposed to low dose irritant fumes cough but do not wheeze. Am f Respir Crit Care Med 1997;156:206-10.

15 Lara-Marquez ML, Deykin A, Krinzman S, et al. Analysis of $\mathrm{T}$ cell activation after bronchial allergen challenge in patients with atopic asthma. 7 Allergy Clin Immunol 1998:101:699-708

16 Kolpp-Sarda MN, Bene MC, Massin N, et al. Altered partition of $\mathrm{T}$ cell subsets in the peripheral blood of workers exposed to flour dust. Am F Ind Med 1995;28:497-504.

17 Sprince NL, Oliver LC, McLoud TC, et al. Asbestos exposure and asbestos-related pleural and parenchymal disease. Asociations with immune imbalance. Am Rev Respir Dis 1991;143:822-8.

18 Sprince NL, Oliver LC, McCloud TC, et al. T cell alveolitis in lung lavage of asbestos-exposed subjects. Am F Ind Med 1992;21:311-19

19 Crotty TB, Myers JL, Katzenstein AL, et al. Localised malignant meothelioma. A clinicopathalogic and flow cytometric study. Am F Surg Pathol 1994;18:357-63.

20 Holian A, Uthman MO, Goltsova T, et al. Asbestos and silica-induced changes in human alveolar macrophage phenotype. Environ Health Perspect 1997;105(suppl 5):113942.

21 Noguera A, Busquets X, Sauleda J, et al. Expression of adhesion molecules and $G$ proteins in circulating neutrophils in chronic obstructive pulmonary disease. Am $\mathcal{7}$ Respir Crit Care Med 1998;158:1664-8.

22 de Jong JW, van der Belt-Gritter B, Koeter GH, et al. Peripheral blood lymphocyte cell subsets in subjects with chronic obstructive pulmonary disease: association with smoking, IgE and lung function. Respir Med 1997;91:6776 .

23 Bergamaschi E, Smargiassi A, Mutti A, et al. Immunological changes among workers occupationally exposed to sytrene. Int Arch Occup Environ Health 1995;67:165-71.

24 Dales R, Miller D, White J, et al. Influence of residential fungal contamination on peripheral blood lymphocyte populations in children. Arch Environ Health 1998;53:190-5.

25 Muller-Suur C, Larsson K, Malmber K, et al. Increased number of activated lymphocytes in human lung following swine dust inhalation. Eur Respir f 1997;10:376-80.

26 Bergstrom CE, Eklund A, Skold M, et al. Bronchoalveolar lavage findings in fire-fighters. Am f Ind Med 1997;32:332-6.

27 Pinkerton LE, Biagini RE, Ward EM, et al. Immunologic findings among lead-exposed workers. Am f Ind Med 1998; 33:400-8.

28 Yurkow EJ, Makhijani PR. Flow cytometric determination of metallothionein levels in human peripheral blood lymphocytes: utility in environmental exposure assessment. f Toxicol Environ Health 1998;54:445-57.

29 Gould JRM, Beckett P, Curran AD. Increase in CD14 expression on monocytes following exposure to endotoxin. Biomarkers 1998;3:73-9.

30 Elms J, Allan L, Pengelly I, et al. In vitro response to colophony fume: relevance to in vivo sensitisation [abstract]. Immunology 1998;95:110-10.

\section{Correspondence and editorials}

Occupational and Environmental Medicine welcomes correspondence relating to any of the material appearing in the journal. Results from preliminary or small scale studies may also be published in the correspondence column if this seems appropriate. Letters should be not more than 500 words in length and contain a minimum of references. Tables and figures should be kept to an absolute minimum. Letters are accepted on the understanding that they be subject to editorial revision and shortening.

The journal also publishes editorials which are normally specially commissioned. The Editor welcomes suggestions regarding suitable topics; those wishing to submit an editorial, however, should do so only after discussion with the Editor. 